\title{
MEDIATION ADVOCACY
}

\section{LLM RESEARCH PAPER}

LAWS 536: NEGOTIATION AND MEDIATION

\section{FACULTY OF LAW}

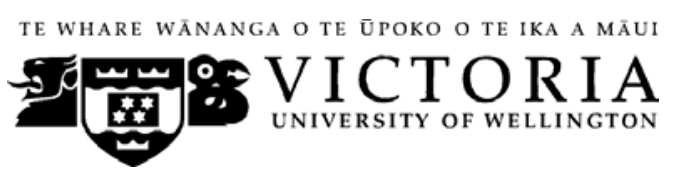

2014 


\section{Contents}

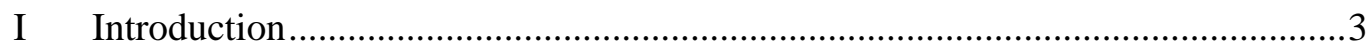

II Adversarial Approach ....................................................................................

III Reasons for the Adversarial Approach ...............................................................

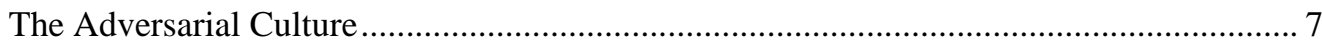

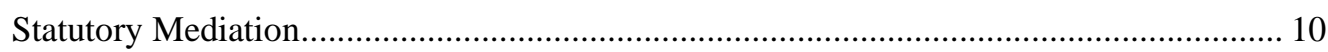

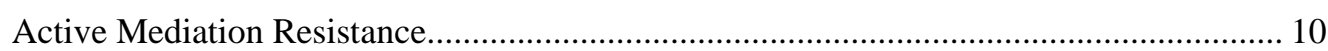

Achieving "Results"....................................................................................................... 11

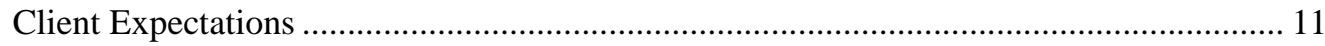

Lawyer Personality ......................................................................................................... 12

Economic Considerations …………………………………………………………….. 13

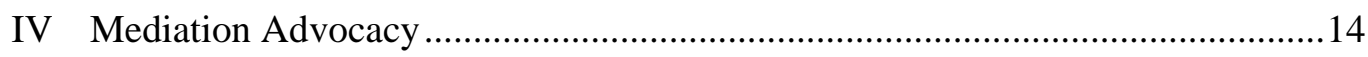

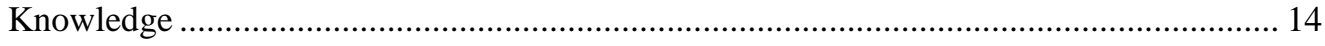

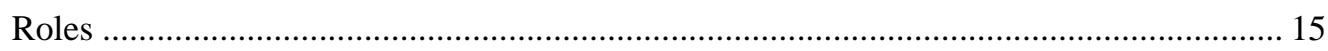

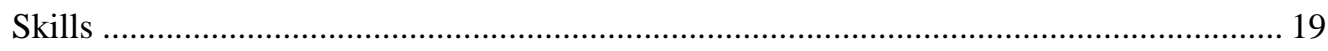

V Shifting to Mediation Advocacy ..........................................................................20

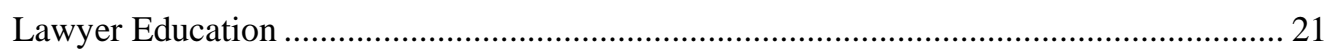

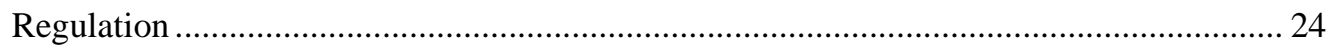

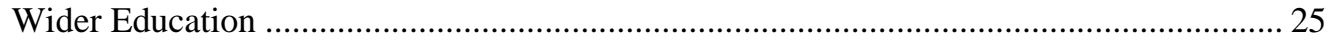

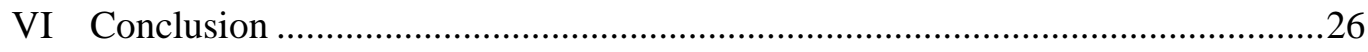

VII Bibliography …………………………………………………………28

The text of this paper (excluding table of contents, footnotes and bibliography) comprises approximately 7,337 words. 


\section{Introduction}

Mediation has been a part of New Zealand's employment statutory framework in one form or another for over a century, and has been the first port of call for employment disputes under the current Employment Relations Act for nearly 15 years. ${ }^{1}$ I have been working as a mediator in this context for almost seven years in more than 1,000 mediations.

Lawyers are playing a significant part in the field of mediation, with a large number representing clients in this forum on a regular basis. In an evaluation of 100 of my mediations over a ten-month period, $85 \%$ of parties were legally represented. This rate is consistent with anecdotal reporting across the employment mediation service.

Lawyer representation in mediation is not unique to the employment context. There are various mediation schemes provided for under many New Zealand statutes as well as a wide raft of non-statutory mediation occurring in numerous settings. In my experience as a mediator with human rights and leaky building mediations, as well as working as a lawyer in a large commercial law firm, I am aware lawyers are representing clients in many other areas of mediation as well.

Although there is a significant amount of mediation occurring and a large number of lawyers regularly appearing in mediation, my experience is that the majority of lawyers act in mediation as if they were in litigation and take an adversarial approach. My thesis is that lawyers have not adapted effectively to mediation and taken on the role of mediation advocacy.

This paper explores the topic by first describing, in Part II, what I observe as lawyers' adversarial approach in mediation. It then looks at other research to assess whether this experience is reflective of a wider issue. It finds there is evidence to support my observations. Part III analyses why lawyers are operating in an adversarial way in mediation and proposes several reasons this may be the case. Part IV puts forward what I propose is appropriate mediation advocacy. It sets out the knowledge, roles and

\footnotetext{
${ }^{1}$ Grant Morris "Towards a History of Mediation in New Zealand’s Legal System" (2013) 24 Australasian Dispute Resolution Journal 86 at 89 - 90.
} 
skills required from lawyers when representing clients in mediation. Part V suggests what might be done to assist a shift away from the common, adversarial approach to effective mediation advocacy.

This paper is written within the context of employment mediation in New Zealand. However, it draws on research from different jurisdictions and areas of practice so the conclusions it comes to may have more general application.

The topic is not whether lawyers should be in mediation. I am not arguing that lawyers do not have a part to play in mediation. A lawyer well versed in mediation advocacy can play a highly effective part in the process. Leonard Riskin, one of the key authors on the topic of lawyers in mediation, expresses this even more strongly, saying he believes lawyers' involvement is fundamental to mediation's success. ${ }^{2}$ Further, this paper is focused on lawyers representing parties in mediation and does not consider lawyers as mediators.

\section{Adversarial Approach}

Some researchers argue mediation and litigation are not actually so different and therefore the approach required of lawyers as representatives in mediation is not dissimilar from that required within litigation. ${ }^{3}$ I strongly contest that view. Consideration of the key elements of these two processes demonstrates the clear differences. Mediation is a process through which the parties work together with the assistance of a neutral third party to address their issues in a problem-solving manner to come to a consensual resolution between themselves. Litigation is an adversarial process through which one party wins and the other loses as decided by a third party on the basis of legal rights, with the outcome imposed on the parties.

\footnotetext{
${ }^{2}$ Leonard Riskin “Mediation and Lawyers” (1982) 43 Ohio St L J 29 at 41.

${ }^{3}$ Bobette Wolski “An Evaluation of the Current Rules of Professional Conduct Governing Legal Representatives In Mediation in Australia and the United States and of a Range of Proposed Alternative ‘Non-Adversarial’ Ethics Systems for Lawyers” (PhD, Bond University, 2011).
} 
The differences between litigation and mediation may not be as drastic or simplistic as they are often expressed but the key features set out above make it apparent that there are some fundamental differences in the very nature of these two processes. To further highlight the central distinctions: mediation is based on principles of party empowerment and self-determination, the issues in dispute may not be rights based, there is no third party decision maker, and resolution can only be achieved through mutual agreement. This is clearly a very different process to litigation and, as such, requires a different approach.

By its very nature, mediation is a diverse and flexible process. This diversity can be seen reflected in the very broad range of disputes that are mediated within the employment context. This includes cases that have been referred from the Employment Court, collective bargaining, personal grievances and on-going employment relationship problems. Each of these disputes will require something slightly different in terms of mediation process. This flexibility can render it difficult to make generalised statements about mediation. However, the elements referred to above capture the fundamental principles that underpin any mediation. ${ }^{4}$

Over the course of my career as a mediator, I have seen lawyers from across the experience spectrum, from those who have recently graduated to those who have been practising for decades. In my opinion, the majority of them have not mastered the art of mediation advocacy. Rather, they take an adversarial approach in mediation.

By ‘adversarial approach’ I mean lawyers acting in mediation as though they are in litigation. Bryan Clark, the author of Lawyers and Mediation, one of the central texts on this topic, defines adversarial as "partisan, competitive and aggressive behaviours." ${ }^{5}$ What I observe includes lawyers acting in mediation as if they are trying to persuade a third party decision maker of the strength of their rights based

\footnotetext{
${ }^{4}$ There is one exception to this within the employment regime. Mediators operating under the Employment Relations Act 2000 have the ability to make binding decisions and recommendations. However, I consider these processes to be med-arb, not mediation, and am not including them in this paper's considerations.

${ }^{5}$ Bryan Clark Lawyers and Mediation (Springer, New York, 2012) at 48.
} 
position. They present 'cases' in mediation, often aggressively, as if they were submissions in court. As such, they are law-centric, with an exclusive focus on their clients' legal rights as opposed to their wider interests. They are also lawyer-centric, concentrating on their own dominant role as opposed to allowing or encouraging essential client focus and participation.

There is not a large amount of research on lawyers in mediation. Aside from Clark's recent work on this topic, the other comprehensive and influential text is Julie Macfarlane's book The New Lawyer. ${ }^{6}$ Despite the lack of a sizeable body of research, there is scholarly support that suggests the adversarial approach is not unique to New Zealand's employment mediations. Macfarlane's 2001 research on mediation in Canada identified a large number of lawyers who believed their traditional, adversarial role should continue in mediation. ${ }^{7}$ Clark makes reference to more recent and comprehensive research of lawyers in Canada and the United States that identified practice norms that are "not conducive to effective client advocacy in mediation."8

Further research in Canada found lawyers dominated the process and sidelined their clients, to the extent nonattendance by the clients themselves was usual. ${ }^{9}$ Australia's National Alternative Dispute Resolution Council (NADRAC) 2009 Annual Report refers to Australian research that found: "There is also a strong view that the conduct of some participants in ADR processes, often legal practitioners, leaves much to be desired." ${ }^{10}$ Clark sites further research from wide ranging jurisdictions, including New Zealand, Israel and the United Kingdom, as evidence of lawyers persisting with standard adversarial lawyering in mediation. ${ }^{11}$

\footnotetext{
${ }^{6}$ Julie Macfarlane, The New Lawyer (UBC Press, Vancouver Toronto, 2008).

${ }^{7}$ Julie Macfarlane “Culture Change? A Tale of Two Cities and Mandatory Court-Connected Mediation” (2002) 22 J Disp Resol 241.

${ }^{8}$ Clark, above n 5, at 108 .

${ }^{9}$ Tamara Relis, Perceptions in Litigation and Mediation: Lawyers, Defendants, Plaintiffs, and Gendered Parties (Cambridge University Press, New York, 2009) at section 1.2.

${ }^{10}$ National Alternative Dispute Resolution Advisory Council Annual Report (2009) at 171.

${ }^{11}$ Clark, above n 5, at 111-113.
} 
This seemingly common adversarial approach demonstrates a lack of basic understanding of the nature of mediation, for example, aggressive adversarial behaviours show a failure to appreciate the importance of the relationship with the other party and the need to work with them in order to reach resolution. This lack of understanding and persistent use of an adversarial approach impacts on the efficacy of mediation. As Clark states, it "renders it [mediation] a pale shadow of its potential optimum.”12 Other research has found it fails to meet clients' needs. ${ }^{13}$ Additionally, in my experience, it means parties are less likely to achieve a truly beneficial resolution. This is supported by empirical research that found parties are less likely to reconcile with each other in the presence of adversarial lawyers. ${ }^{14}$

\section{Reasons for the Adversarial Approach}

Many of the lawyers I see in mediation have attended numerous mediations. The fact they take an adversarial approach is not because mediation is a new process to which they have not had a chance to adjust. Nor is it a trait unique to older lawyers who may have started practising prior to the development of mediation. It is a consistent approach I observe being taken by lawyers of all levels of experience in practice. In this way, the adversarial approach appears to be pervasive within the profession. The next part of this paper considers why this may be.

\section{The Adversarial Culture}

One of the most obvious and often-mentioned reasons for lawyers' adversarial approach is that the legal culture is one of litigation and adversary. It is argued that lawyers are trained and practice within this culture and it is therefore naturally their inherent approach.

An adversarial pursuit of clients' legal rights has been the basis of the legal profession's role over the many centuries of its existence. It has had many years to

\footnotetext{
${ }^{12}$ Clark, above n 5 , at 177 .

${ }^{13}$ Relis, above $\mathrm{n} 9$, at 17.

${ }^{14}$ Jean Poitras, Arnaud Stimec and Jean-Francois Roberge "The Negative Impact of Attorneys on Mediation Outcomes: A Myth or a Reality?” (2010) 26(1) Negotiation Journal 9.
} 
become engrained as a culture. ${ }^{15}$ The modern-day, traditional legal culture is often defined with reference to the "zealous advocacy" model. This term originated from the American Bar Association’s 1969 'Model Rules of Professional Conduct.' In its purest form zealous advocacy has been described as "doing anything and everything that is lawful in order to advance the clients' interests” with the singular goal being pursuit of rights. ${ }^{16}$

In his seminal work of 1982, Riskin expresses the legal culture in terms of "the lawyer's standard philosophical map." ${ }^{17} \mathrm{He}$ explains this is based on two central underlying tenets of "adversariness and rule solubility." 18 He further says that this culture encourages the development of cognitive abilities over emotional ones as well as not being in tune with personal interconnections and nonmonetary values. ${ }^{19}$ Clark defines the legal culture as a "default to rights paradigm” in which the lawyer is in control and central to the process and outcome. ${ }^{20}$ Macfarlane expresses the same idea in defining current legal practice as a culture of adjudication. Similarly to Clark, she says this is based on three core professional beliefs: default to rights, justice as process, and lawyers in charge. ${ }^{21}$ She says these principles are the basis of the current "norms of legitimacy"22 for the profession, meaning they make up the idea of what a good lawyer is.

Writers argue that this adversarial culture begins in legal education, where, as Clark states, the "traditional, narrow, adversarial role of the lawyer as 'zealous advocate' has been prevalent”. ${ }^{23}$ Riskin expresses a similar view, saying a “... dominant, source of the popularity of the standard map is legal education, which is thoroughly pervaded

\footnotetext{
${ }^{15}$ Macfarlane, above n 6, at 101.

${ }^{16}$ Macfarlane, above n 6, at 98.

${ }^{17}$ Riskin, above n 2, at 43 .

${ }^{18}$ Riskin, above $\mathrm{n} 2$, at 44 .

${ }^{19}$ Riskin, above n 2, at 45 .

${ }^{20}$ Clark, above n 5, at 57.

${ }^{21}$ Macfarlane, above n 6, at 47.

${ }^{22}$ Macfarlane, above n 6, at 19.

${ }^{23}$ Clark, above n 5, at 103.
} 
by this vision.” 24 Macfarlane refers to a similar concept when she says that law students are driven by and striving towards the 'norms of legitimacy' as defined above.

Scholars talk about the adversarial culture that is introduced in law schools then being reinforced by communities and habits of practice. ${ }^{25}$ Macfarlane says it can be seen reflected in and supported by professional codes of conduct. ${ }^{26}$ Writing specifically about employment mediation in New Zealand, Karen Radich and Peter Franks make reference to the same culture of practice. They talk of lawyers' "adversarial behaviour patterns they have learned in the course of their professional life."27 Macfarlane goes further by arguing this culture extends evens deeper than what is learnt or practiced. She proposes the adversarial culture is fundamental to lawyers' professional identify and makes up a part of their basic values, norms and beliefs. ${ }^{28}$

The adversarial legal culture does not only exist within the profession. It is a view that is held by the general public and reinforced through the media. Most reporting involving the legal profession is in relation to court cases and is framed in terms of who has won or lost. The adversarial culture is also reflected in fictional depictions of lawyers through popular books, television series and movies. Macfarlane believes these depictions create and reinforce a strong stereotypical image of adversarial lawyers fighting for rights. ${ }^{29}$ In writing about the popular culture depictions of negotiations, Carrie Menkle-Meadow identifies the dangers inherent in perpetuating particular misconceptions about the law as adversarial and competitive. As she states: ${ }^{30}$

\footnotetext{
${ }^{24}$ Riskin, above n 2 , at 48 .

${ }^{25}$ Clark, above n 5, at 50; and Macfarlane, above n 6, at 34 .

${ }^{26}$ Macfarlane, above n 6, at 42.

${ }^{27}$ Karen Radich with Peter Franks, Employment Mediation ( $2^{\text {nd }}$ ed, Brookers, Wellington, 2013) at 51.

${ }^{28}$ Macfarlane, above n 6, at 28.

${ }^{29}$ Macfarlane, above n 6, at 26.

${ }^{30}$ Carrie Menkel-Meadow “Legal Negotiation in Popular Culture: What Are We Bargaining For?” in Michael Freeman (ed) Law and Popular Culture: Current Legal Issues (Oxford University Press, London, 2005) at 603.
} 
If the general population and potential would-be lawyers continue to eat from this limited fare they will continue to think that law is always a battleground, whether in the courtroom or at the conference table.

The perceptions held by the general public further compound and strengthen the adversarial culture.

This examination of what the legal culture is and where it comes from shows the adversarial approach lies at the very heart of the profession. There is an inherent rights based culture within the basis of legal education, reinforced through practice and existing in the general public's mind. This creates a very strong default, one that is directly at odds with mediation. As Riskin expresses it: ${ }^{31}$

The two assumptions of the lawyer's philosophical map (adversariness of parties and rule-solubility of dispute), along with the real demands of the adversary system and the expectations of many clients, tend to exclude mediation from most lawyers' repertoires.

\section{Statutory Mediation}

Employment mediation is an example of 'institutionalised' mediation. It has been created through statute as a part of the dispute resolution framework. If a matter does not settle at mediation the next step is an adversarial process. The majority of employment mediations involve personal grievances, that is, legal claims. This context makes mediation harder to distinguish from the adversarial processes and even more susceptible to the default approach of the adversarial culture. This reinforces lawyers taking a unitary view of the employment system and only seeing employment disputes as legal disputes.

\section{Active Mediation Resistance}

There is some argument that the adversarial approach is not being taken subconsciously but that lawyers are actively resisting mediation. Clark discusses this proposition at some length. He states that a number of lawyers see mediation as a direct challenge to their jobs and industry and are therefore deliberately resisting a

\footnotetext{
${ }^{31}$ Riskin, above n 2, at 44 .
} 
change in approach that they consider undermines their roles. ${ }^{32}$ Clark talks of others who have a view that mediation is a "soft" option and oppose participating in way that might be perceived as "weakness". ${ }^{33}$

\section{Achieving "Results"}

A high number of matters settle in employment mediation. The Ministry of Business Innovation and Employment's 2012-2013 Annual Report puts this settlement rate at $82 \% .{ }^{34}$ This may be taken as evidence that what lawyers are currently doing in mediation is working and therefore reinforces their approach. As a mediator, I often see that although matters do resolve it might not be the best resolution that would have been available if lawyers had taken a different approach. There are often lost opportunities in resolutions, especially in terms of relationships and often in relation to financial settlements. My observation in this regard is supported by the evidence discussed in relation to the impact of the adversarial approach in Part II above, showing it fails to meet clients' needs and means parties are less likely to reconcile.

\section{Client Expectations}

There is research to show that an adversarial approach is what clients are likely to expect from their lawyer. Macfarlane supposes the highly adversarial and partisan stereotype is what people believe they want when faced with a problem they want to win. ${ }^{35}$ There is evidence to show the adversarial approach is a self-fulfilling prophecy. Research by Linda Mulcahy found that lawyers acted more adversarially in mediation than when dealing directly with the other side's lawyers outside of the process, partially because of their perceived idea of how their clients expected them to act. ${ }^{36}$ Riskin makes a similar point, saying the consistency between clients’ expectations

\footnotetext{
${ }^{32}$ Clark, above n 5 , at 47.

${ }^{33}$ Clark, above n 5 , at 54 .

${ }^{34}$ Ministry of Business Innovation and Employment Annual Report (2012-2013) at 98.

${ }^{35}$ Macfarlane, above n 6, at 27.

${ }^{36}$ Linda Mulcahy “Can Leopards Change Their Spots: The Role of Lawyers in Mediation” (2001) 8(3) International Journal of the Legal Profession 203.
} 
and lawyers' behaviour is one of the factors that strengthens the 'philosophical map'. ${ }^{37}$

\section{Lawyer Personality}

A number of researchers refer to the lawyer personality as a factor in the adversarial approach. Riskin submits the congruency between lawyers' personalities and the philosophical map is one of the reasons it is so strong. ${ }^{38}$ Clark is of the same view, writing that, "many of the traditional traits of lawyers ... are inherent personality types commonly found in those with a predisposition to study law.»39

Susan Daicoff has done significant research in this area, reviewing the empirical research on lawyers' personalities. She found evidence to show that, compared to other people, law students are more dominant, self-confident and desirous of leadership; less affiliative; place less emphasis on feelings and emotions and more on rationale-based decision making. Daicoff argues that these traits drive zealous advocacy. They are also in direct contrast with some of the fundamental elements of mediation, such as consensual, client-focus, and creative problem solving. ${ }^{40}$ Jean Sternlight has also looked at lawyers’ psychological make-up. She found evidence to show lawyers tend to be "rational and analytical, somewhat cynical, verbal and not particularly creative" and that they "tend to see themselves as gladiators, fighting for a particular cause or to protect their clients.” ${ }^{41}$ These traits are consistent with an adversarial approach and contradictory to mediation.

\footnotetext{
${ }^{37}$ Riskin, above n 2, at 47.

${ }^{38}$ Riskin, above n 2 , at 47.

${ }^{39}$ Clark, above n 5, at 103.

${ }^{40}$ Susan Daicoff Lawyer Know Thyself: A Psychological Analysis of Personality Strengths and Weaknesses (American Psychological Association, Washington, 2004).

${ }^{41}$ Jean R Sternlight “Lawyers' Representation of Clients in Mediation: Using Economics and Psychology to Structure Advocacy in a Nonadversarial Setting” (1999) 14(2) Ohio St J on Disp Resol 269 at $323-324$.
} 


\section{Economic Considerations}

The economic basis of contemporary legal practice has been identified as another influence underlying the adversarial approach. A number of writers talk about the impact the commercial focus of the profession has on practice. Riskin believes the hourly-rate basis of legal practice's economic structure perpetuates lawyers' adversarial approach. He talks specifically about mediation in relation to this concept, saying it creates an economic threat to lawyers, as resolving a matter in mediation as opposed to litigation not only reduces the fees earned in relation to the current dispute but also future disputes if mediation repairs and improves relationships. ${ }^{42}$ In this way, Riskin draws a link between economic considerations and active resistance to mediation mentioned above.

Riskin is not the only author to examine this issue. Clark claims there is some empirical foundation for: 'the general argument that lawyers' behaviour in the dispute resolution context may be shaped, amongst other things, by economic considerations ..." ${ }^{43}$ He refers to research that found the billable hour regime drives adversarial practice by maximising lawyers' time and therefore fee potential. ${ }^{44}$ Macfarlane also writes on the topic, saying: "Adversarial notions of zealous advocacy offer a highly efficient strategy for lawyers working in a fee-for-service capacity within the modernday legal system.” ${ }^{45}$ She believes this profit-motivated, contemporary system has created a more adversarial model of practice. ${ }^{46}$ It appears the economic structure of contemporary practice does nothing to diminish the adversarial approach. However, lawyers are bound by formal professional rules of conduct that oblige them to serve their clients. ${ }^{47}$ Acting on the basis of personal economic motivation would clearly breach these obligations.

The various factors identified above provide an immutable foundation for, and perpetuating reinforcement of, the adversarial approach. This examination

\footnotetext{
${ }^{42}$ Riskin, above n 2, at 48 .

${ }^{43}$ Clark, above n 5 , at 43 .

${ }^{44}$ Clark, above n 5, at 40-42.

${ }^{45}$ Macfarlane, above n 6, at 102.

${ }^{46}$ Macfarlane, above n 6, at 103.

${ }^{47}$ Lawyers and Conveyancers Act (Lawyers: Conduct and Client Care) Rules 2008 ch 6.
} 
demonstrates the inherent strength of this approach. It provides a clear picture as to why lawyers are continuing to act adversarially in mediation.

\section{Mediation Advocacy}

As mentioned above, some researchers argue mediation and litigation are not that different and therefore neither are the roles. ${ }^{48}$ I strongly contest this view. There may be some overlap in terms of skills but mediation advocacy is an entirely different function, not merely an extension of advocacy in litigation.

The inherent flexibility of the mediation process coupled with the variety of contexts mediation occurs within makes proscription of lawyer best practice within this process not only difficult but also undesirable. The diversity of mediation requires a diversity of behaviour dictated by many different considerations. These considerations can be vast and complex. The type of dispute, people involved and stage of dispute will all be relevant. Conflict, personalities and context are too complex to dictate a 'one size fits all' approach. However, there is a general level of knowledge, a number of roles and set of skills that make up appropriate mediation $\operatorname{advocacy.}^{49}$

\section{Knowledge}

Knowledge is a fundamental requirement of mediation advocacy. Lawyers cannot properly carry out their role in mediation unless they understand the context in which they are operating. A conceptual understanding of the theories of mediation, negotiation and conflict provides the necessary appreciation of the nature of mediation. A thorough comprehension of the process itself is also required.

\footnotetext{
${ }^{48}$ Wolski, above $\mathrm{n} 3$.

${ }^{49}$ Menkel-Meadow believes the term 'mediation advocacy' is an oxymoron (Carrie Menkel-Meadow “Ethics in ADR Representation: A Road Map of Critical Issues” (1997) 4 Disp Resol Mag 3 at 3). I believe it is valid, as lawyers are required by their ethical duties to advocate for their clients in mediation, albeit in a different form as that required by, and appropriate for, litigation. My use of the term is also in part because it is the simplest and clearest way to refer to the role of lawyers representing clients in mediation.
} 
Understanding the different steps of mediation and the purpose of each helps clarify the appropriate approach. This theoretical underpinning leads to an understanding of how to appropriately apply the roles and skills required of mediation advocacy, and how to adjust to different circumstances that may present themselves through mediation.

It is also important for lawyers to have an understanding of any law relating to the particular process, such as up-to-date knowledge of the current legal position on confidentiality in employment mediation. Familiarity with the relevant ethics and how they apply in mediation is also necessary. This includes the Rules of Conduct and Client Care and, in the employment context, the statutory requirements of good faith behaviour. Further, knowledge of any law relating to the subject matter of the dispute is important. As discussed below, part of the lawyer's role is to provide advice and discuss alternatives to settlement, both of which require an understanding of the law.

\section{Roles}

One of the similarities between mediation and litigation is the importance of preparation. Pre-mediation preparation is vital. It is usually focused on lawyers preparing their clients. This is important and is addressed below. However, I would argue in light of the issues discussed in this paper that lawyers' self-preparation is equally, if not more, important.

This requires lawyers to consciously shift their mind-set from an adversarial approach to mediation advocacy. It also entails preparing for the fact that at times mediation advocacy may feel counter-intuitive or require resisting the default of the more traditional, 'hardwired' legalistic approach. In her research, Linda Mulcahy talks about the strength of lawyers' natural instinct even despite their good intentions beforehand. ${ }^{50}$ Another aspect of self-preparation for lawyers is turning their minds to how they will respond if met with an adversarial approach on the other side. This can make it even harder not to revert to the more familiar approach.

\footnotetext{
${ }^{50}$ Mulcahy, above n 36, at 214-217.
} 
Preparing clients for mediation is also a vitally important part of mediation advocacy. It is particularly important because of the client focus of mediation and the fact lawyers will often hold all of the information about the process. As Riskin states, lawyers are the "initial consultants in dispute processing." 51 They therefore have a great deal of power to influence clients' understanding of mediation and their approach to it. Even when clients have had previous experience in mediation, lawyers are in a position to shape the clients' approach.

Client preparation involves a number of important aspects. Firstly, the lawyer should provide clear and thorough information about both the theory and process of mediation. This should include a specific explanation that mediation is not litigation. Secondly, the lawyer should explain and encourage client participation. Thirdly, they should explain their own role as lawyer in mediation. It is important that clients understand they will not see their lawyer acting as zealous advocate. In fact, they may even see them working with the other side. It is important clients understand why this is the case. This is especially important given the impacts of client expectation, and even presence, as discussed above.

Preparing the content of a dispute for mediation involves a number of components. It is important for lawyers to have a clear understanding of the background and all of the issues. This does not just include the legal points. However, these are often relevant and having the necessary documents and details can be important too. Once this is done, lawyers should help their clients identify their needs or interest. These are not legal rights and entitlements. Examples of non-legal interests are reputational, economic, psychological, social and relationship considerations. Once these have been identified, lawyers should work with their clients, in the context of those needs, to identify the goals they have for the mediation. They then need to take clients through the same process in relation to the other party: thinking about what their needs and goals might be.

Lawyers also need to help their client to start the process of considering the alternatives to resolving the matter in mediation so they have some basis for this

\footnotetext{
${ }^{51}$ Riskin, above n 2 , at 42 .
} 
discussion in mediation. A discussion about how to handle emotions may also be an important part of preparation. Taking the needs and goals into account, lawyers should then assist clients in preparing their opening comments. ${ }^{52}$ It is particularly important for a lawyer to guide their client to ensure these comments are appropriate to the process. They should be prepared bearing the nature of mediation in mind. These comments should include an explanation of the issues from the clients' perspective, any relevant legal points, and what the client would like to achieve. Thought should be given to who is going to present them, the client and or the lawyer. There are pros and cons to each option and it will depend on the particular circumstances. Understanding and articulating these is a part of the lawyer's role.

Mediation advocacy may involve other pre-mediation functions as well, such as choosing a mediator or drafting ADR clauses. However, neither of these is relevant within the context of statutorily provided schemes. They would be more relevant in commercial and private mediations.

Pre-mediation preparation is so important because it sets the foundation for what happens during the mediation process. There are many elements to mediation advocacy during mediation. Managing the client relationship is one of these. Client involvement is central in mediation. There is an overarching role in continuing to encourage client participation and ownership. This has been expressed as "facilitating, supporting and enabling the client to participate effectively."53 Macfarlane explains the relationship required in mediation advocacy as a "working partnership." 54 She says this type of relationship balances client loyalty and creative consensus building, making both possible. This addresses the tension between protection and participation that some writers express concern about. ${ }^{55}$ This type of relationship also requires lawyers to act as role models and coaches for their clients through out mediation.

\footnotetext{
${ }^{52}$ These are often referred to as opening statements (see Radich with Franks, above n 27 for example). However, this is litigation language and I therefore prefer the alternative.

${ }^{53}$ Samantha Hardy and Olivia Rundle Mediation for Lawyers (CCH Australia Limited, Sydney, 2010) at 167.

${ }^{54}$ Macfarlane, above n 6, at 109.

${ }^{55}$ For example, Jacqueline Nolan-Haley “Lawyers, Clients, and Mediation” (1997-1998) 73 Notre Dame L Rev 1369 at 1381.
} 
Persuasive oral advocacy is another key role in mediation advocacy. It is not the same role that is required in litigation. It is directed towards a very different audience: the other party, not a judge or jury. It necessitates persuading this other party to agree to reach resolution. This is not best achieved through adversarial positioning and threats. The first and most powerful opportunity for this persuasion is through clients' opening comments, as discussed above. Good mediation advocacy during the process also requires lawyers to advise their clients as necessary and articulate legal issues as appropriate. However, understanding and allowing the important place of emotions on both sides is also important.

Having a negotiation strategy is another essential role of mediation advocacy. It starts at the very beginning of the process. There is no point in beginning mediation with an adversarial attack and then asking for cooperation in resolving the matter. Rather than telling the other party they are wrong, lawyers should focus on persuasion and creating uncertainty. The negotiation style may shift along the collaborative to competitive scale as the situation requires. This goes back to the importance of theoretical understanding and knowing what to do, when and why.

Another important role during mediation is building on the work done in preparation to help the client identify possible solutions. This should include consideration of non-legal possibilities. Lawyers should understand and utilise the processes brainstorming and evaluating to help identify these options. They also need to work through a process of risk assessment with their clients. This involves identifying and discussing the BATNA and WATNA. ${ }^{56}$ These assessments should not be just confined to legal outcomes. They should be more holistic and take all elements into consideration. Radich and Franks provide a comprehensive list of these factors including legal costs, emotional costs, opportunity costs, and publicity. ${ }^{57}$ This provides a framework for considering the options that arise through the process. This step may also include allowing the mediator to do some reality testing with the client.

\footnotetext{
${ }^{56}$ Roger Fisher, William Ury and Bruce Patton Getting to Yes: Negotiating Agreement Without Giving In (Random House Business Books, London, 2003).

${ }^{57}$ Radich with Franks, above n 27, at 66.
} 
In the concluding stages of the mediation, lawyers may have a role in drafting agreements reached at mediation. This will be more so if the agreement is a s 149 legal settlement as opposed to a behavioural agreement that is more likely in the case of on-going employment relationship problems. It is the mediator's role to explain the final and binding nature of mediated agreements under s 149 of the Employment Relations Act 2000. However, a lawyer should assist to ensure their client fully understands this.

Post mediation, the 'working partnership' between lawyers and clients in mediation advocacy suggests lawyers have a role in following up with clients to address any concerns they may have, whether the matter was resolved in mediation or not. There will also be a role for lawyers dealing with any settlement enforcement issues.

Skills

Macfarlane and Wolski claim that many of the skills required as part of mediation advocacy fall within lawyers' generally required skill set of the traditional role. ${ }^{58} \mathrm{I}$ agree with this view. However, these existing skills are required to be applied in different ways in a new context. There are also some skills required by mediation advocacy that do not fall within the traditional role.

Communication skills are a good example of existing skills. Good lawyers should already possess effective communication skills, including listening, questioning and explaining. However, within mediation advocacy this skill set becomes fundamental. Macfarlane defines it as the "primary vehicle" of advocacy. ${ }^{59}$ This requires that the traditionally held skills be developed and enhanced. Mediation advocacy requires active listening and exploratory questioning specifically designed to elicit needs and interests of all involved. It can also require sophisticated delivery of difficult messages.

Communication skills are related to a new set of skills that can be termed 'relationship management'. This includes the ability to build trust and rapport as well

\footnotetext{
${ }^{58}$ Macfarlane, above n 6, at 20; and Wolski, above n 3, at 153.

${ }^{59}$ Macfarlane, above n 6, at 23.
} 
as emotional intelligence, a set of skills Macfarlane articulates as including empathy, self-awareness, optimism and impulse-control. ${ }^{60}$ It requires lawyers to understand underlying emotions and be able to focus on others' needs. This is not just relevant in terms of the key role a client has in mediation but also in light of the central role the other party and their lawyer has in mediation.

Persuasive ability is also a more traditional legal skill. However, as outlined above, in mediation lawyers need to be able to persuade another party to agree as opposed to a judge. In this way, mediation advocacy requires persuasion skills that encompass more than just a rights-based approach.

Advanced negotiation skills are obviously central to mediation advocacy. These skills feature in traditional lawyering practices but are at the very centre of the mediation process. Within this process they require a shift away from the traditional competitive style to a cooperative model. Macfarlane sees negotiation skills as a core dimension. She talks about them requiring both cognitive and emotional abilities and qualities. ${ }^{61}$ Creative problem solving is a related skill that is also necessary.

Mediation advocacy is comprehensive and sophisticated. It requires a thorough understanding of mediation theory as well as a wide range of complex roles and skills.

\section{$V$ Shifting to Mediation Advocacy}

The strength and pervasiveness of the adversarial approach outlined in Part III paints an almost bleak picture for mediation advocacy. However, I do not believe this should prevent attempts from being made to improve the situation. As Menkel-Meadow says: “... I persist in a prescriptive vision that lawyering can be made better and used for better purposes.”62 Moreover, understanding where the adversarial approach stems from and why it is so robust provides guidance in how it may be changed.

\footnotetext{
${ }^{60}$ Macfarlane, above n 6, at 23.

${ }^{61}$ Macfarlane, above n 6, at 113.

${ }^{62}$ Carrie Menkel-Meadow "Lawyer Negotiations: Theories and Realities - What We Learn From Mediation” (1993) 56 The Modern Law Review 361 at 378.
} 
I do not think more mediation is the answer. Nor is it leaving it to the lawyers to adjust. Lack of progress to date and consistency in the lawyers I see shows that change is not happening naturally over time. Clark sets out evidence to show some jurisdictions are further ahead than others in terms of acceptance of mediation. However, the fact or prevalence of mediation is not enough to change beliefs, which is required to change practice. ${ }^{63}$ This part of the paper suggests some ways this change may be achieved.

\section{Lawyer Education}

Analysis of the adversarial approach highlights the important role legal education plays in shaping the profession. Riskin and Clark both identify legal training as a contributor to lawyers' "proper involvement” in mediation. ${ }^{64}$ One of Riskin's key conclusions is that: "Mediation education for lawyers is essential if our society is to make the best use of mediation.”65 Macfarlane also highlights the importance of legal education, calling it a critical "site of change" in shifting from the old adversarial model. ${ }^{66}$ Mediation education at university is of key importance. Macfarlane argues that law schools must take on a role of leadership in changing the profession. ${ }^{67}$ In her recent critique of legal education, Menkel-Meadow identifies the growth of mediation as a key change in the legal landscape. She calls for education to keep pace, stating: "Legal education must adapt to new conditions of the profession and to the changing social conditions of our society ...”68

A number of writers call for mediation to be a core subject, as opposed to a discretionary component of legal education as it more commonly is; if it exists at all. ${ }^{69}$ Clark notes this when commenting that progress has been made in legal education

\footnotetext{
${ }^{63}$ Clark, above n 5, at 57.

${ }^{64}$ Riskin, above n 2, at 30 .

${ }^{65}$ Riskin, above n 2 , at 57.

${ }^{66}$ Macfarlane, above n 6, at 223.

${ }^{67}$ Macfarlane, above n 6, at 225.

${ }^{68}$ Carrie Menkel-Meadow "Crisis in Legal Education or the Other Things Law Students Should be Learning and Doing” (2013) 45 McGeorge L Rev 133 at 134.

${ }^{69}$ Clark, above n 5, at 178.
} 
around the world but usually by way of "optional, 'bolt-on' subjects”. ${ }^{70}$ I agree there is a need to have a core mediation subject that includes mediation advocacy training. Further than this, I think mediation should be incorporated in all subjects in order to integrate it across the entire legal culture. This would mean including mediation as a part of classes in employment, family, commercial, human rights and so on.

Clark laments "the lack of underpinning of mediation in standard legal education across the world ..."71 An examination of available mediation education within New Zealand's law schools makes it apparent this country is no exception to Clark's lamentation. Waikato and AUT, two of the smaller law faculties, are the only schools within New Zealand to have compulsory dispute resolution courses. However, both of these are relatively generalist papers including mediation along with adjudication, arbitration and negotiation. I do not believe this allows the necessary depth of teaching on mediation. Additionally, they are senior papers, which means students are not exposed to mediation until the latter stages of their education. Mediation is available as an elective course through Auckland and Victoria, although these too are senior level papers. The other larger faculties, Canterbury and Otago, do not offer mediation courses. Sadly, this current academic landscape looks very much the same for mediation as it did twenty years ago. There is much room for improvement in mediation education within New Zealand law faculties.

What is taught is obviously important as well. A mix of practical and theory is necessary. Although traditional law academia may be resistant to skills based teaching, practice is an important aspect of mediation advocacy training. Courses should include development of key skills as outlined above, including communication, problem solving, brainstorming, relationship management, oral persuasion and so on. Riskin also talks about the importance of "experiential" learning as well as theoretical. ${ }^{72}$ Suzanne Schmitz's extensive review of mediation

\footnotetext{
${ }^{70}$ Clark, above n 5, at 108.

${ }^{71}$ Clark, above n 5, at 178.

${ }^{72}$ Riskin, above n 2, at 50.
} 
education supports this. She found, "students learn best about dispute resolution processes through experiential methods."73

Universities need to look at increasing practice opportunities for students. Clinical legal education may be one way to achieve this. It is a popular model in the United States and could be set up in New Zealand. Student mediation competitions are another way for students to gain experience. The annual International Chamber of Commerce Mediation Competition provides such an opportunity. Although law schools are able to apply to attend directly, establishing a national competition for New Zealand universities would encourage much wider involvement, as well as raise the profile of mediation advocacy within the legal academy.

Although they have a large role to play, mediation education is not solely the responsibility of law schools. There are a number of stages within legal education that need to incorporate mediation advocacy training. The Professional Legal Studies courses are also a good opportunity for practical experience and skills development. However, it should not be seen as something to be left entirely to this forum. The limited length of these courses and the late stage they occur in lawyers' education mean it is not enough to suggest mediation training belongs in these courses alone. They should be building on, reinforcing and finessing what was started in law school.

Further, this education should not end once lawyers are admitted to the Bar. Development of mediation advocacy should be sustained through continuing education. The New Zealand Law Society continuing legal education programme currently provides two mediation-related workshops but these are only available in Wellington and Auckland. Mediation professional bodies, such as LEADR and AMINZ, can also provide this type of education opportunity. As with universitybased education, there is not much in the way of mediation advocacy training for lawyers and there is real room, and need, for growth in this area.

\footnotetext{
${ }^{73}$ Suzanne Schmitz "What We Should Teach in ADR Courses?: Concepts and Skills for Lawyers Representing Clients in Mediation” (2001) 6 Harv Negot L Rev 189 at 195.
} 
Clark claims that mediation practice has been proven to change a lawyer's "suitability for mediation”. ${ }^{74}$ On this basis, lawyers should be seeking more practice opportunities. Networking or special interest groups may be useful ways to facilitate this. Mentoring programmes that pair lawyers experienced in mediation advocacy with recent graduates provides new lawyers with possible practice opportunities as well as exposing them to positive influence. Establishing such programmes could be a role for the Law Society and the mediation professional bodies. These organisations are best placed to reach established lawyers. Law firms should also be seeking out ways to facilitate these opportunities internally. Riskin suggests experiential learning for lawyers should include them gaining experience in the role of mediator. ${ }^{75}$ This could be provided by mediator training courses available through the professional bodies.

Increasing the resources on mediation advocacy would also contribute to improving education. Schmitz's 2001 examination of ADR textbooks found although there was some development occurring, there was still limited material available for lawyers focusing specifically on mediation advocacy. ${ }^{76}$ Although I was able to find some material in researching this paper, there is still much room for research and writing on this topic.

\section{Regulation}

Some writers propose that lawyer behaviour in mediation requires regulation through mediation-specific ethics. Those in support of the proposition claim clear guidelines on conduct in mediation will help to shape and ensure appropriate mediation advocacy. Menkel-Meadow is one of these. She believes: "new and evolving lawyer roles require new rules and practices." 77 Others, such as Wolski, have a differing perspective. She does not believe the legal profession needs new rules to govern lawyers' conduct in mediation on the basis the roles are not so different and existing

\footnotetext{
${ }^{74}$ Clark, above n 5, at 104.

${ }^{75}$ Riskin, above n 2, at 50 .

${ }^{76}$ Schmitz, above n 73, at 196.

${ }^{77}$ Carrie Menkel-Meadow “Is the Adversary System Really Dead? Dilemmas of Legal Ethics as Legal Institutions and Roles Evolve” (2004) 57 Current Legal Problems 84 at 106.
} 
ethics can apply. ${ }^{78}$ My view is that the roles are different and legal rules of conduct may need to evolve as part of a wider and more general legal cultural change away from the adversarial culture. However, I think the current rules are wide enough to apply to mediation advocacy and change will be most effectively led through education initially, making regulation less of a priority at this stage.

\section{Wider Education}

The examination of what lies behind the adversarial approach in Part III shows that clients have a role to play in this situation. What they expect or, in some cases, even want from their lawyers has an impact on lawyers' approach. This provides an opportunity to extend the sphere of influence over lawyers to change. My argument is that steps should be taken to widen everyone's 'philosophical maps' to include an alternative approach to conflict from the traditional legalistic reaction. Educating the general population reaches potential clients as well as lawyers. This increases the scope for creating a difference. It also shifts the responsibility for that change solely from the lawyers. The President of the Supreme Court in the United Kingdom, Lord Neuberger, endorses this view, stating: "Public legal education, including mediation education, is of fundamental importance. More needs to be done in that direction."79

There is some evidence to show steps are being taken in this direction. Examples of relevant programmes can be found within the general education system. The Cool Schools Peer Mediation programme is one of them. This programme teaches children conflict resolution skills and processes. It was established by the Peace Foundation in 1991 and has been run in two thirds of schools throughout New Zealand. ${ }^{80}$ Another example is the Schools Conflict Resolution and Mediation (SCRAM) initiative in Australia. This programme was established in 2001 by the Western Australian Dispute Resolution Association to build skills and understanding about dispute resolution. It is an interactive role-play mediation competition for 14 and 15 year old high school students. It has been estimated that the programme has impacted 3,500

\footnotetext{
${ }^{78}$ Wolski, above n 3.

${ }^{79}$ Lord Neuberger Has Mediation Had its Day? (The Gordon Slynn Memorial Lecture 2010, 10 November 2010) at [35].

${ }^{80}$ The Peace Foundation “Cool Schools” < www.peace.net.nz>.
} 
people. ${ }^{81}$ The federal Western Australian Curriculum Council endorses the programme so it goes towards student accreditation. The impact and efficacy of these types of programmes could be enhanced by making them core, as opposed to discretionary, requirements of the curriculum.

Opportunities outside of the education system to expose the general public to mediation should also be sought out. Clark talks about the importance of promoting mediation generally to increase understanding and acceptance. ${ }^{82}$ This was an aspect of NADRAC's role in Australia. ${ }^{83}$ This type of body could add benefit in New Zealand. Mediation promotion is also another role for mediation professional bodies.

An understanding of why the adversarial approach is so pervasive highlights the importance of mediation education and exposure. This is not only true for lawyers but for society generally. As expressed by Lord Neuberger, "The need for greater education, both of the public and the legal profession, is one of the key challenges for the future." 84

\section{Conclusion}

In 1982 Riskin argued that lawyers were fundamental in realising the benefits of mediation. He said their understanding of mediation, and ability and willingness to participate was crucial to the success of mediation. He believed achieving that would require lawyers to make a fundamental shift away from their "philosophical map”, ${ }^{85}$

This argument was made over twenty years ago and has been echoed by a number of writers over the years since. It is my view that this shift has not occurred. The majority of the lawyers I observe are continuing to take an adversarial approach in

\footnotetext{
81،The History of SCRAM” 2010 <www.ecu.edu.au/_data/assets/pdf_file/0017/163241/SCRAM-A-

Celebration.pdf $>4$.

${ }^{82}$ Clark, above n 5, at 133.

${ }^{83}$ Australian Attorney-General's Department “Legal System - Alternative Dispute Resolution”

$<$ www.ag.gov.au>.

${ }^{84}$ Neuberger above $n$ 79, at [29].

${ }^{85}$ Riskin, above n 2, at 43.
} 
mediation. They may be adapting their adversarial approach but they have not shifted to appropriate mediation advocacy. There is no evidence to indicate that shift is imminent. Indeed, there is a risk the philosophical map of the process will be shifted instead. A continued insistence on bringing an adversarial approach to mediation may distort the process by undermining its fundamental nature and benefits. Mediation within legislative frameworks may be at particular risk to this influence. As Clark describes it, cultural change is a "two way street" and traditional, adversarial legal culture is already influencing mediation. ${ }^{86}$ Jacqueline Nolan-Haley believes there is a directional shift being exerted on mediation by adversarial legal practice and mediation "stands at a crossroads" ${ }^{87}$ in this regard. This provides impetus for urgent change.

Macfarlane argues lawyers' shift to mediation advocacy requires a new application of old skills as opposed to a paradigm shift. ${ }^{88}$ Wolski makes a similar claim. ${ }^{89}$ I believe something more drastic is required. The adversarial culture of the profession is one of the central reasons an adversarial approach persists in mediation. It must shift before real change can be realised. I am not alone in this view. Clark provides numerous examples of research from various jurisdictions saying cultural change is necessary. ${ }^{90}$ He summarises the position by stating that changes in behaviour without a change in belief system do not lead to culture change..$^{91}$

Mediation has been a part of the justice system for decades and lawyers are yet to master mediation advocacy. The status quo has been in existence long enough to conclude that it is not achieving the necessary uptake of mediation advocacy. A cultural shift within the legal profession is required for this to truly occur. Given mediation's current place at the crossroads, this shift needs to begin now.

\footnotetext{
${ }^{86}$ Clark, above n 5, at 57.

${ }^{87}$ Jacqueline Nolan-Haley "Mediation: The "New Arbitration" (2012) 17 Harvard Negotiation Law Review 61 at 61.

${ }^{88}$ Macfarlane, above n 6, at 20.

${ }^{89}$ Wolski, above n 3, at 153.

${ }^{90}$ Clark, above n 5, at 55.

${ }^{91}$ Clark, above n 5 , at 57.
} 


\section{Bibliography}

\section{A Legislation}

Employment Relations Act 2000

Lawyers and Conveyancers Act (Lawyers: Conduct and Client Care) Rules 2008

\section{B Books and Chapters in Books}

Bryan Clark, Lawyers and Mediation (Springer, London, 2012).

Susan Daicoff Lawyer Know Thyself: A Psychological Analysis of Personality Strengths and Weaknesses (American Psychological Association, Washington, 2004).

Tim Dare The Counsel of Rogues? A Defence of the Standard Conception of the Lawyer's Role (Ashgate, Surrey, 2008).

Roger Fisher, William Ury and Bruce Patton Getting to Yes: Negotiating Agreement Without Giving In (Random House Business Books, London, 2003).

Samantha Hardy and Olivia Rundle Mediation for Lawyers (CCH Australia, Sydney, 2010).

Julie Macfarlane, The New Lawyer (UBC Press, Toronto, 2008).

Carrie Menkel-Meadow "Legal Negotiation in Popular Culture: What Are We Bargaining For?” in Michael Freeman (ed) Law and Popular Culture: Current Legal Issues (Oxford University Press, London, 2005).

Karen Radich with Peter Franks, Employment Mediation ( $2^{\text {nd }}$ ed, Brookers, Wellington 2013).

Tamara Relis, Perceptions in Litigation and Mediation: Lawyers, Defendants, Plaintiffs, and Gendered Parties (Cambridge University Press, New York, 2009).

David Spencer and Michael Brogan, Mediation Law and Practice (Cambridge University Press, New York, 2006). 


\section{Journal Articles}

Tom Arnold "20 Common Errors in Mediation Advocacy” (1995) 13 Alternatives to the High Cost of Litigation 69.

John S Dzienkowski "Lawyering in a Hybrid Adversary System” (1996) 38 Wm \& Mary L Rev 45.

Julie Macfarlane "Culture Change? A Tale of Two Cities and Mandatory CourtConnected Mediation” (2002) 22 J Disp Resol 241.

Carrie Menkel-Meadow "Lawyer Negotiations: Theories and Realities - What We Learn From Mediation” (1993) 56 The Modern Law Review 361.

Carrie Menkel-Meadow "Ethics in ADR Representation: A Road Map of Critical Issues” (1997) 4 Disp Resol Mag 3.

Carrie Menkel-Meadow "Is the Adversary System Really Dead? Dilemmas of Legal Ethics as Legal Institutions and Roles Evolve” (2004) 57 Current Legal Problems 84.

Carrie Menkel-Meadow "Crisis in Legal Education or the Other Things Law Students Should be Learning and Doing” (2013) 45 McGeorge L Rev 133.

Grant Morris "Towards a History of Mediation in New Zealand's Legal System" (2013) 24 Australasian Dispute Resolution Journal 86.

Linda Mulcahy "Can Leopards Change Their Spots: The Role of Lawyers in Mediation (2001) 8(3) International Journal of the Legal Profession 203.

Jacqueline Nolan-Haley “Lawyers, Clients, and Mediation” (1997-1998) 73 Notre Dame L Rev 1369.

Jacqueline Nolan-Haley "Mediation: The "New Arbitration" (2012) 17 Harvard Negotiation Law Review 61.

Jean Poitras, Arnaud Stimec and Jean-Francois Roberge "The Negative Impact of Attorneys on Mediation Outcomes: A Myth or a Reality?” (2010) 26(1) Negotiation Journal 9. 
Suzanne Schmitz "What We Should Teach in ADR Courses?: Concepts and Skills for Lawyers Representing Clients in Mediation” (2001) 6 Harv Negot L Rev 189.

Jean R Sternlight “Lawyers' Representation of Clients in Mediation: Using economics and Psychology to Structure Advocacy in a Nonadversarial Setting” (1999) 14(2) Ohio St J on Disp Resol 269.

Leonard Riskin “Mediation and Lawyers” (1982) 43 Ohio St L J 29 at 41.

Leonard Riskin “Decisionmaking in Mediation: The New Old Grid and the New New Grid” (2003) 79 Notre Dame Law Review 1.

Jonnette Watson-Hamilton, "The Significance of Mediation For Legal Education” (1999) 17 Windsor Y B Access Just 280.

Roselle Wissler "Representation in Mediation: What we Know from Empirical Research” (2010) 37 Fordham Urban Law Journal 419.

\section{Reports}

Larry Richard Herding Cats: The Lawyer Personality Revealed in Altman Weil Report to Management (August 2002).

Ministry of Business Innovation and Employment Annual Report (2012-2013).

National Alternative Dispute Resolution Advisory Council Annual Report (2009).

\section{E Dissertations}

Bobette Wolski “An Evaluation of the Current Rules of Professional Conduct Governing Legal Representatives in Mediation in Australia and the United States and of a Range of Proposed Alternative 'Non-Adversarial' Ethics Systems for Lawyers” (PhD, Bond University, 2011).

\section{F Internet Resources}

Australian Attorney-General's Department “Legal System - Alternative Dispute Resolution" <www.ag.gov.au> 
“The History of SCRAM” 2010

<www.ecu.edu.au/_data/assets/pdf_file/0017/163241/SCRAM-A-Celebration.pdf > 4.

The Peace Foundation "Cool Schools” < www.peace.net.nz>.

\section{G Other Resources}

Lord Neuberger Has Mediation Had its Day? (The Gordon Slynn Memorial Lecture 2010, 10 November 2010). 